\title{
Newer approaches in the treatment of asthma
}

\author{
Kamlesh P. Patel ${ }^{*}$, Harsh M. Joshi, Varsha J. Patel
}

Department of Pharmacology, Smt. NHL Municipal Medical College, Ellisbridge, Ahmedabad-380006, Gujarat, India

Received: 26 September 2012 Revised: 28 September 2012

Accepted: 30 September 2012

\section{*Correspondence to:}

Dr. Kamlesh P. Patel,

E-mail:

drkamleshp@yahoo.com

\begin{abstract}
Asthma is a worldwide public health problem. The most effective antiasthmatic drugs - inhaled $\beta 2$-agonists and glucocorticoids controls asthma in about $90-95 \%$ of patients. However, severe glucocorticoid-dependent and resistant asthma presents a great clinical burden. Therefore, reducing glucocorticoids - related adverse effects using novel steroid-sparing agents is needed. Furthermore, the mechanisms involved in the persistence of inflammation are poorly understood and the reasons why some patients have severe life threatening asthma and others have very mild disease are still unknown. Although glucocorticoids effectively control the inflammatory process in asthma, they have little effect on the lower airway remodeling processes that appear to play a role in the pathophysiology of asthma. Several new drugs developed to target specific components of the inflammatory process in asthma [e.g. anti-IgE antibodies (omalizumab), cytokines and/or chemokines antagonists, immunomodulators, antagonists of adhesion molecules)], have not yet been proven to be particularly effective. Hence, considering the central role of $\mathrm{T}$ lymphocytes in the pathogenesis of asthma, drugs targeting disease-inducing Th2 cells are promising future therapeutic strategies. Some of these new anti-asthmatic treatment approaches may in the future not only control symptoms and modify the natural course of asthma, but also potentially prevent or cure the disease. Hence, the development of novel drugs may allow resolution of these changes.
\end{abstract}

Keywords: Antiasthamatics, Anti-IgE antibodies, Cytokines, Chemokines, Immunomodulators, Glucocorticoids

\section{INTRODUCTION}

Asthma is an increasingly global public health problem affecting more than 300 million people and causing 2,50,000 deaths worldwide. It is caused by genetic and environmental factors ${ }^{1}$ and is characterized by reversible airflow obstruction, but in some patients with chronic asthma there may be an element of irreversible airflow obstruction which is difficult to manage. Drugs for treatment of asthma are divided into two category- fast acting drugs such as short acting $\beta 2$-agonists (SABA) ${ }^{2}$ i.e. salbutamol and terbutaline; anticholinergic ipratropium bromide and drugs for long term control such as long acting $\quad \beta 2$-agonists $(\mathrm{LABA})^{3,4} \quad$ i.e. salmeterol; glucocorticosteroids. The other drugs used are Leukotriene antagonists (montelukast, zafirlukast) and Mast cell stabilizers (cromolyn sodium). The current asthma therapies are not cures since the anti-asthmatic drugs have little effect on the lower airway remodeling processes and hence the symptoms return soon after the treatment is stopped. Therefore, development of novel drugs may allow resolution of these changes. Drug development for asthma has been directed at improving currently available drugs and findings new compounds.

\section{NEWER APPROACHES}

\section{Drugs which inhibit phosphodiesterase-4}

A target of novel anti-inflammatory treatments for asthma is the selective inhibitors of phosphodiesterase 4 (PDE4). PDE4 is present in neutrophils, T cells, macrophages and airway smooth muscle cells. ${ }^{5}$ A drug which inhibits hydrolysis of intracellular cAMP and finally it causes bronchodilation and anti-inflammatory effect. There are many newer compounds in this new class of drugs; however most of the clinical studies reported high effectiveness with cilomilast and roflumilast. ${ }^{5}$ 
CCR3 (Chemokine receptors) antagonists targeting Th2 cells in asthmatic airways

CCR3 activation causes activation and proliferation of eosinophils via action on specific CCR3 receptors. New compound NNY-CCL14 is resistant to degradation by CD26/dipeptidyl peptidase IV (DP4) which is effective in treatment of asthma. ${ }^{6}$ It causes internalization of CCR3 receptor and inhibits calcium release. Inhaled TPIASM8 is a new compound which has two RNA targeting nucleotides against the CCR3 receptor. It also has and the common $\beta$ subunit for the receptors of IL-3, 5 and GMCSF (Figure 1).

\section{CRTH2 antagonists}

CRTH2 is chemoatract receptor molecule on Th2 cells. Ramatroban is an orally active drug which is antagonist of tromboxan (Tx) A2. It is also an antagonist for CRTH2, and in vitro it inhibits migration of eosinophils due to prostaglandins. It is effective for bronchial hyperresponsiveness due to prostaglandin D2 in humans and it reduce antigen- induced early- and late-phase inflammatory responses in animal models of asthma. ${ }^{7}$

\section{Sphingosine 1-phosphate receptor agonists (S1P1R)}

It causes decrease in $\mathrm{T}$ cell proliferation and cytokine production. S1P decreases CD4 T cell generation of IFN- $\gamma$ and IL-4. ${ }^{8}$ FTY720, an oral immunosuppressant is a derivative of myriocin and is very effective because it causes sequestration of lymphocytes in lymphoid tissue. It also decreases number of dendritic cells.

\section{Transcription factor modulators (NF- $\kappa$ B and AP-1)}

$\mathrm{NF}-\kappa \mathrm{B}$ and AP-1 plays pivotal role in inflammation of bronchial mucosa and triggers signs and symptoms. Molecule which inhibits AP-1 transcription also reduces eosinophil infiltration and excessive secretion and mucosal damage. It does not affect NF- $\kappa$ B. PNRI-299 is effective in a mouse asthma model. ${ }^{9}$

\section{STAT-1 blocker}

The intracellular signaling intermediate signal transducer and activator of transcription (STAT1) causes many effects of IFN- $\gamma$ and it is thought to be the activation of Tbet which regulates Th1 differentiation. Development of decoy oligo-nucleotides AVT-01 inhibits STAT1 activity. In an animal model of asthma a single application of this STAT1 decoy oligo-nucleotides significantly reduces airway hyper-responsiveness, hyper-secretion and edema. $^{10}$

\section{STAT-6 blocker}

Niflumic acid, an antisense oligo-nucleotide of STAT-6 blocks calcium-activated chloride channel. It also inhibits airway hyper-responsiveness, BAL eosinophilia and eotaxin, IL-13-induced hyperplasia of cells and MUC5AC expression. It inhibits activation of STAT-6 in epithelial cells of bronchi. ${ }^{10}$

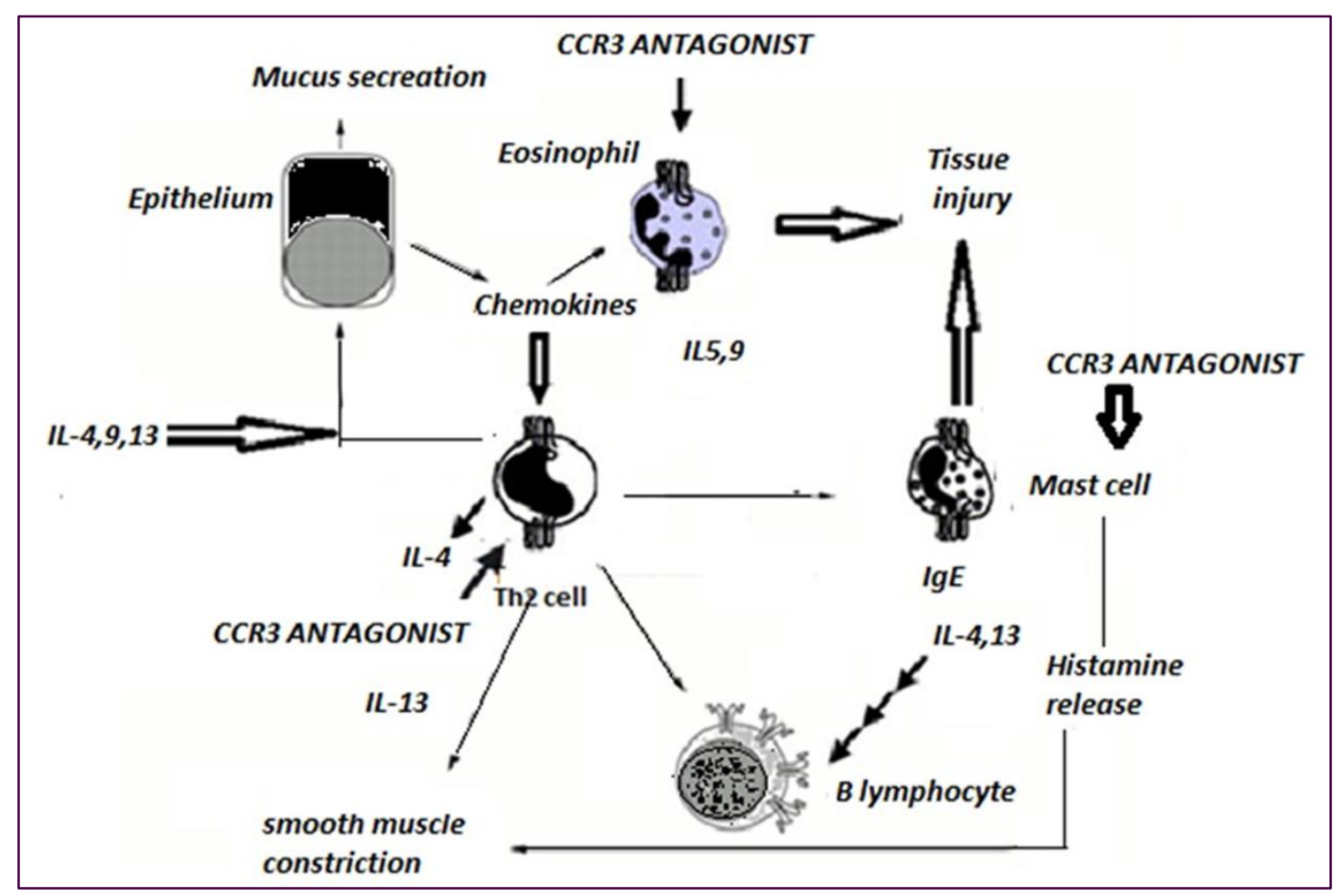

Figure 1: Action of T helper type 2 (TH2)-type cytokines and mechanism of CCR3 antagonist in asthma 


\section{NFATs}

Nuclear factor of activated T cells (NFAT) is a T-cellspecific transcription factor. It is expressed in activated, but not resting $\mathrm{T}$ cells and is required for IL-2 gene transcription. Bis (trifluoromethyl) pyrazoles (BTPs) inhibits Th1 and Th2 cytokines production. ${ }^{11}$ So it has significant antiinflammatory effect. It was first act as inhibitors of IL-2 synthesis; BTPs also inhibits IL-2 production with a 10 -fold enhancement over cyclosporin A. it has advantage of inhibiting IL-4, IL-5, IL-8, and CCL11 production. ${ }^{11}$

\section{Peroxisome proliferator-activated receptors}

PPAR- $\gamma$ has inhibitory effect on IL-5 from $\mathrm{T}$ cells activated in vitro. ${ }^{12}$ In animal models it is revealed that after induction of allergic asthma, mice given oral ciglitazone, a potent synthetic PPAR- $\gamma$ ligand, it is observed that it reduces inflammation and hyper-secretion and hyper-responsiveness. Effectiveness also shows on re-challenge with allergen, reduces production of IFN- $\gamma$, IL-4, and IL-2 in T cells.

\section{Modulators of the synthesis or action of key pro- inflammatory Th2 cell cytokines}

\section{IL-4 blockers}

Novel agent, the development of pascolizumab (SB 240683), a humanized anti-interleukin-4 antibody, as well as of a blocking variant of human IL-4 (BAY36-1677) has apparently been discontinued due to adverse events.

\section{IL-13 blockers}

By inhibition of IL-13, prevents the development of airway hyperresponsiveness after allergen, along with a strong eosinophilic response. ${ }^{13,14}$ Newer agent R121D/Y124D (pitrakinra, BY-16-9996, Aerovant) is an anti-human IL-13 antibodies. It is used for severe asthma.

\section{IL-5 blockers}

Novel Humanised anti-IL-5 antibodies have been developed. Only single i.v. infusion of mepolizumab significantly reduces blood and sputum eosinophilia for several months in severe asthma.

\section{Heparin-like molecules}

Heparin along with histamine, which is synthesized, stored and released from mast cells. A closely related molecule heparan sulphate is expressed, as part of a proteoglycan, on cell surfaces and throughout tissue matrices. ${ }^{15}$ Heparin related molecules have significant anti-inflammatory effects in vitro and in animal models of asthma. ${ }^{15}$ The inhalation of heparin prevents exerciseinduced bronchoconstriction. IVX 0142, which is heparin derived oligosaccharide. ${ }^{15}$

\section{Immunosuppressants}

\section{Methotrexate and Cyclosporin A}

Methotrexate does not inhibit number of eosinophils and other inflammatory cells in blood and mucosa but that the steroid-sparing effect of methotrexate is achieved by modification of cell function. Cyclosporin A inhibits IL-5 and GM-CSF which was triggered by allergens and other environmental factors. ${ }^{16}$ Cyclosporin A also act on $\mathrm{T}$ cell proliferation and inhibits its action. It also inhibits IL-2, IL-4, and IL-5 by human CD4+ helper T cells, and IL-5 production. ${ }^{16}$

\section{Others}

\section{Surfactant proteins}

In animal models of asthma, treatment with surfactant proteins can inhibits pulmonary cellular infiltration IgE levels, eosinophilia and cause a marked shift from a Th2 to a Th1 cytokine profile. Novel surfactant protein, Suplatast tosilate, inhibits IL-4 and IL-5 production from allergen-stimulated human Th2 lymphocytes in vitro. It also prevents goblet-cell metaplasia and modify inflammatory mediators induced eosinophil chemotaxis and adhesion of eosinophils to endothelial cells.

\section{$\beta_{2}$-adrenergic agonists}

In asthma patients LABA should be used if the patient is receiving along with ICS. There is little advantage to be gained by improving beta- 2 receptor selectivity because most of the side effects of these agents are due to beta- 2 receptor stimulation like muscle tremor, tachycardia and hypokalemia. Newer once daily inhaled beta- 2 agonists, such as indacaterol and carmoterol, are now in clinical development.

\section{Magnesium sulfate}

In patients with acute severe asthma magnesium sulfate (MgSO4) can be used to relieve bronchoconstriction. In severe attacks of asthma (forced expiratory volume in 1 second $\left[\mathrm{FEV}_{1}\right]<30 \%$ of predicted value), magnesium sulfate used intravenous or nebulized. ${ }^{17}$ When added to nebulized beta- 2 agonist, it markedly improve lung functions and reduce hospital admissions. ${ }^{17}$ The treatment is cheap and well tolerated.

\section{$\mathbf{K}^{+}$channel openers}

After depolarization, during recovery of excitable cells $\mathrm{K}^{+}$ channels plays a major role. These channels also have role in stabilization of cells. Cromakalim or levcromakalim causes hyperpolarization and relaxation of airway smooth muscle by opening $\mathrm{K}^{+}$channels. ${ }^{18}$

\section{Atrial natriuretic peptides}

Atrial natriuretic peptide (ANP) activates membranebound guanylyl cyclase and increases cellular cyclic GMP, leading to bronchodilation. ANP and the related peptide urodilatin relieve bronchoconstriction in asthma. Its effects are in accordance with beta- 2 agonists. ${ }^{19}$

Vasoactive intestinal polypeptide analog 
VIP is 28 amino acid peptide which binds to both $\mathrm{VPAC}_{1}$ and $\mathrm{VPAC}_{2}$. These are $\mathrm{G}$ protein couple receptors. It stimulates adenylyl cyclase-cAMP-PKA pathway leading to relaxation of smooth muscle. It is potent bronchodilator. It may not as effective during acute attacks because it is very short acting. So in search of longer acting analog, Ro 25-1533 have selective action to stimulates VIP receptors in airway smooth muscle (via the $\mathrm{VPAC}_{2}$ receptor). Inhaled Ro 25-1533 is rapid acting and relieve symptoms of asthma. ${ }^{20}$

\section{New corticosteroids}

It is known that corticosteroids have several systemic adverse effects. So in search of a molecule which has fewer adverse effects but rapidly metabolized in bronchial mucosa, soft steroids discovered. Butixocort and tipredane are metabolized too rapidly to achieve sufficient concentration and duration to cause an anti-inflammatory effect. So newer approach to develop corticosteroids that dissociate the DNA-binding effect of corticosteroids. ${ }^{21}$

\section{Mitogen-activated protein kinase inhibitors}

MAP kinase pathways are of major importance in chronic inflammation. $^{22}$ There are 3 major pathways. These pathways are blocked by SB203580 and RWJ67657. These are newer group of interest in clinical trials. They inhibit different inflammatory cytokines, chemokines, and inflammatory enzymes. ${ }^{23}$

\section{PIP 3 kinase inhibitor}

As PIP 3 kinase activation causes calcium release, so its inhibitors decrease calcium release. Newer molecules such as wortmannin, LY29002 which relieves bronchoconstriction.

\section{Refilling of sarcoplasmic reticulum}

It causes maintenance of sarcoplasmic reticulum calcium level by deactivate tyrosine kinase. Such compounds are Cyclopiazonic acid and Thapsigargin.

\section{REFERENCES}

1. Martinez FD. Genes, environments, development and asthma: a reappraisal. Eur Respir J 2007;29:17984.

2. Rodrigo GJ, Nannini LJ. Comparison between nebulized adrenaline and beta2 agonists for the treatment of acute asthma. A meta-analysis of randomized trials. Am J Emerg Med 2006;24:21722.

3. Cates CJ, Lasserson TJ, Jaeschke R. Regular treatment with salmeterol and inhaled steroids for chronic asthma: serious adverse events. Cochrane Database Syst Rev 2009;(3):CD006922.

4. U.S. Food and Drug Administration. FDA Drug Safety Communication: New safety requirements for long-acting inhaled asthma medications called LongActing Beta-Agonists (LABAs), February 2010. Available at http://www.fda.gov/Drugs/DrugSafety/PostmarketD
rugSafetyInformationforPatientsandProviders/ucm2 00776.htm. Accessed 19 September 2012.

5. Karagiannidis C, Ruckert B, Hense G, Willer G, Menz G, Blaser K,Schmidt-Weber CB. Distinct leucocyte redistribution after glucocorticoid treatment among difficult-to-treat asthmatic patients. Scand J Immunol 2005;61:187-96.

6. Forssmann U, Hartung I, Balder R, Fuchs B, Escher SE, Spodsberg N, Dulkys Y. n-Nonanoyl-CC chemokine ligand 14, a potent $\mathrm{CC}$ chemokine ligand 14 analogue that prevents the recruitment of eosinophils in allergic airway inflammation. J Immunol 2004;173:3456-66.

7. Sugimoto $H$, Shichijo $M$, Iino $T$, Manabe $Y$, Watanabe A, Shimazaki M, Gantner F, Bacon KB. An orally bioavailable small molecule antagonist of CRTH2, ramatroban (BAY u3405), inhibits prostaglandin D2-induced eosinophil migration in vitro. J Pharmacol Exp Ther 2003;305:347-52.

8. Dorsam G, Graeler MH, Seroogy C, Kong Y, Voice JK, Goetzl EJ. Transduction of multiple effects of sphingosine 1-phosphate (S1P) on T cell functions by the S1P1 G protein-coupled receptor. J Immunol 2003;171:3500-7.

9. Nguyen C, Teo JL, Matsuda A, Eguchi M, Chi EY, Henderson WR Jr, Kahn M. Chemogenomic identification of Ref-1/AP-1 as a therapeutic target for asthma. Proc Natl Acad Sci USA 2003;100:1169-73.

10. Quarcoo D, Weixler S, Groneberg D, Joachim R, Ahrens B, Wagner AH, Hecker M, Hamelmann E. Inhibition of signal transducer and activator of transcription 1 attenuates allergen-induced air way inflammation and hyperreactivity. J Allergy Clin Immunol 2004;114:288-95.

11. Djuric SW, BaMaung NY, Basha A, Liu H, Luly JR, Madar DJ et al. 3,5-Bis(trifluoromethyl) pyrazoles: a novel class of NFAT transcription factor regulator. J Med Chem 2000;43:2975-81.

12. Mueller C, Weaver V, Vanden Heuvel JP, August A, Cantorna MT. Peroxisome proliferator-activated receptor gamma ligands attenuate immunological symptoms of experimental allergic asthma. Arch Biochem Biophys 2003;418:186-96.

13. Nakano $\mathrm{T}$, Inoue $\mathrm{H}$, Fukuyama $\mathrm{S}$, Matsumoto $\mathrm{K}$, Matsumura M, Tsuda $M$ et al. Niflumic acid suppresses interleukin-13-induced asthma phenotypes. Am J Respir Crit Care Med 2006;173:1216-21.

14. Yang G, Volk A, Petley T, Emmell E, Giles-Komar J, Shang $X$ et al. Anti-IL-13 monoclonal antibody inhibits airway hyperresponsiveness, inflammation and airway remodeling. Cytokine 2004;28:224-32.

15. Ahmed T, Garrigo J, Danta I. Preventing bronchoconstriction in exercise-induced asthma with inhaled heparin. N Engl J Med 1993;329:90-5.

16. Chen Y, Smith ML, Chiou GX, Ballaron S, Sheets MP, Gubbins E, Warrior U, Wilkins J. TH1 and TH2 cytokine inhibition by 3,5bis(trifluoromethyl)pyrazoles, a novel class of 
immunomodulators. Cell Immunol 2002;220:13442.

17. Mohammed S, Goodacre S. Intravenous and nebulised magnesium sulphate for acute asthma: Systematic review and meta-analysis. Emerg Med J 2007;24:823-30.

18. Black JL, Armour CL, Johnson PR et al. The action of a potassium channel activator BRL 38227 (lemakalim) on human airway smooth muscle. Am Rev Respir Dis 1990;142:1384-9.

19. Angus RM, Mecallaum MJ, Hulks G, Thomson NC. Bronchodilator, cardiovascular and cyclic guanylyl monophosphate response to high dose infused atrial natriuretic peptide in asthma. Am Rev Respir Dis 1993;147:1122-5.
20. Linden A, Hansson L, Andersson A et al. Bronchodilation by an inhaled $\operatorname{VPAC}(2)$ receptor agonist in patients with stable asthma. Thorax 2003;58:217-21.

21. Schacke H, Berger M, Rehwinkel H, Asadullah K. Selective glucocorticoid receptor agonists (SEGRAs): Novel ligands with an improved therapeutic index. Mol Cell Endocrinol 2007;275:109-17.

22. Delhase M, Li N, Karin M. Kinase regulation in inflammatory response. Nature 2000;406:367-8.

23. Cuenda A, Rousseau S. p38 MAP-kinases pathway regulation, function and role in human diseases. Biochim Biophys Acta 2007;1773:1358-75. 